\title{
Avaliação da utilização de óleos essenciais de canela, orégano e eucalipto via água de bebida para frangos de corte
}

Evaluation of the use of essential oils of cinnamon, oregano and eucalyptus in drinking water for broilers

Evaluación del uso de aceites esenciales de canela, orégano y eucalipto en agua potable para pollos de engorde

Alicia Dal Santo

ORCID: https://orcid.org/0000-0002-9519-4033 Universidade do Oeste de Santa Catarina, Brasil E-mail: alicia.ds@unoesc.edu.br

Felipe Leite

ORCID: https://orcid.org/0000-0002-7834-4247 Universidade do Oeste de Santa Catarina, Brasil E-mail: leite.felipe00@gmail.com

Fernanda Danieli Antoniazzi Valentini ORCID: https://orcid.org/0000-0002-2868-8498 Universidade do Oeste de Santa Catarina, Brasil E-mail: fernanda_antoniazzi@ hotmail.com

Heloísa Pagnussatt

ORCID: https://orcid.org/0000-0002-0139-9872 Universidade do Oeste de Santa Catarina, Brasil E-mail: heloisa_pagnussatt@hotmail.com

Edemar Aniecevski

ORCID: https://orcid.org/0000-0001-6095-7187 Universidade do Oeste de Santa Catarina, Brasil E-mail: edemar3004@gmail.com

Gabriel Hoinoski

ORCID: https://orcid.org/0000-0003-4396-7935

Universidade do Oeste de Santa Catarina, Brasil E-mail: gabrielhoinoskii@gmail.com

Gilso Mis

ORCID: https://orcid.org/0000-0002-2363-2970

Universidade do Oeste de Santa Catarina, Brasil E-mail: gilso.myss@gmail.com

Milena Fernanda Montagna

ORCID: https://orcid.org/0000-0002-8186-8252

Universidade do Oeste de Santa Catarina, Brasil

E-mail: Milenamontagna@outlook.com

Lucas Eduardo Talian

ORCID: https://orcid.org/0000-0002-0104-8167

Universidade do Oeste de Santa Catarina, Brasil E-mail: lucastalianagro@gmail.com

Alana Birck Ribeiro

ORCID: https://orcid.org/0000-0002-3773-7976

Universidade do Oeste de Santa Catarina, Brasil E-mail: alana.ribeiro@unoesc.edu.br

Aleksandro Schafer da Silva

ORCID: https://orcid.org/0000-0001-5459-3823

Universidade do Estado de Santa Catarina, Brasil

E-mail: aleksandro.silva@udesc.br

Fernando de Castro Tavernari

ORCID: https://orcid.org/0000-0002-3161-019X Embrapa Suínos e Aves, Brasil

E-mail: fernando.tavernari@embrapa.br

Tiago Goulart Petrolli

ORCID: https://orcid.org/0000-0002-6175-5939

Universidade do Oeste de Santa Catarina, Brasil

E-mail: tiago.petrolli@unoesc.edu.br 


\begin{abstract}
Resumo
A restrição ao uso de antimicrobianos como promotores de crescimento na produção de frangos de corte vem se mostrando como um grande desafio. O uso de moléculas alternativas, que apresentam propriedades antimicrobianas, visa substituir estes fármacos. Os óleos essenciais são moléculas com grande potencial para substituir promotores de crescimento. Contudo objetivou-se avaliar o uso de óleos essenciais derivados de Eucalyptus globulus, Cinnamomum zeylanicus e Origanum vulgare via água de bebida para os frangos de corte. Foram utilizados 450 pintos machos da linhagem COBB, estes distribuídos por delineamento experimental, sendo composto por quatro tratamentos constituídos por seis repetições, com 15 animais em cada repetição. $\mathrm{O}$ experimento foi composto por: controle negativo, controle positivo ( $2 \mathrm{ppm}$ flavomicina via ração), óleo de canela + orégano ( $300 \mathrm{ml} / 1000 \mathrm{~L})$, e óleo de eucalipto $(300 \mathrm{ml} / 1000 \mathrm{~L})$. Diferenças foram observadas no desempenho zootécnico $(\mathrm{p}<0,05)$, cujos frangos suplementados com óleo de eucalipto apresentaram peso corporal superior aos alimentados com flavomicina aos 20 dias de idade. Os parâmetros bioquímicos sanguíneos, demonstraram diferença apenas sobre os níveis de ácido úrico na dieta de animais, cujas aves pertencentes ao grupo que recebeu flavomicina demonstraram níveis superiores $(\mathrm{P}=0,038)$ quando comparadas com as aves submetidas aos demais tratamentos. Os demais parâmetros avaliados não sofreram alterações $(\mathrm{P}>0.05)$, assim como os parâmetros histomorfométricos intestinais $(\mathrm{P}>0,05)$. Conclui-se que os óleos essenciais foram capazes de substituir a flavomicina como promotor de crescimento, garantindo adequado desempenho zootécnico e sem afetar a saúde dos animais.
\end{abstract}

Palavras-chave: Desempenho zootécnico; Óleos essenciais; Promotores de crescimento.

\begin{abstract}
The restriction use of antimicrobials as growth promoters in the production of broiler chickens has proven to be a major challenge. The use of alternative molecules, which have antimicrobial properties, aims to replace these drugs. Essential oils are molecules with great potential to replace growth promoters. The objective of this trial was to evaluate the use of essential oils derived from Eucalyptus globulus, Cinnamomum zeylanicus and Origanum vulgare via drinking water for broiler chickens. $450 \mathrm{COBB}$ male chicks were used, distributed by experimental design, consisting of four treatments consisting of six replicates, with 15 animals in each replicate. The experiment consisted of negative control, positive control (2ppm flavomycin via feed), cinnamon oil + oregano $(300 \mathrm{ml} / 1000 \mathrm{~L})$, and eucalyptus oil ( $300 \mathrm{ml} / 1000 \mathrm{~L})$. Differences were observed in zootechnical performance $(\mathrm{p}<0.05)$, whose broilers supplemented with eucalyptus oil had higher body weight than those fed with flavomycin at 20 days of age. The blood biochemical parameters showed difference only on the levels of uric acid in the diet of animals, whose birds belonging to the group that received flavomycin showed higher levels $(\mathrm{P}=0.038)$ when compared to birds submitted to the other treatments. The other parameters evaluated did not change $(P>0.05)$, as well as the intestinal histomorphometric parameters $(\mathrm{P}>0.05)$. It concluded that the essential oils were able to replace flavomycin as a growth promoter, ensuring adequate zootechnical performance and without affecting the animals' health.
\end{abstract}

Keywords: Zootechnical performance; Essential oils; Growth promoters.

\title{
Resumen
}

Restringir el uso de antimicrobianos como promotores del crecimiento en la producción de pollos de engorde ha demostrado ser un gran desafío. El uso de moléculas alternativas, que tienen propiedades antimicrobianas, tiene como objetivo reemplazar estos medicamentos. Los aceites esenciales son moléculas con gran potencial para reemplazar a los promotores del crecimiento. El objetivo de la presente investigación fue evaluar el uso de aceites esenciales derivados de Eucalyptus globulus, Cinnamomum zeylanicus y Origanum vulgare vía agua potable para pollos de engorde. Se utilizaron 450 pollos machos COBB, distribuidos en cuatro tratamientos, compuestos por seis repeticiones, con 15 animales en cada repetición. El experimento consistió en: control negativo, control positivo (2ppm de flavomicina vía pienso), aceite de canela + orégano $(300 \mathrm{ml} / 1000 \mathrm{~L})$ y aceite de eucalipto $(300 \mathrm{ml} / 1000 \mathrm{~L})$. Se observaron diferencias en el desempeño zootécnico $(\mathrm{p}<0.05)$, cuyos pollos de engorde suplementados con aceite de eucalipto tuvieron mayor peso corporal que los alimentados con flavomicina a los 20 días de edad. Los parámetros bioquímicos sanguíneos mostraron diferencia solo en los niveles de ácido úrico en la dieta de los animales, cuyas aves pertenecientes al grupo que recibió flavomicina mostraron niveles más altos $(\mathrm{P}=0.038)$ en comparación con las aves sometidas a los otros tratamientos. Los demás parámetros evaluados no cambiaron ( $\mathrm{P}>0.05)$, así como los parámetros histomorfométricos intestinales ( $\mathrm{P}>0.05)$. Se concluye que los aceites esenciales lograron reemplazar a la flavomicina como promotor del crecimiento, asegurando un adecuado desempeño zootécnico y sin afectar la salud de los animales. Palabras clave: Rendimiento zootécnico; Aceites esenciales; Promotores del crecimiento.

\section{Introdução}

Antimicrobianos são fármacos com ação para o combate de diversas doenças que acometem as espécies. Na produção animal são utilizados de maneira terapêutica, profilática e promotora de crescimento, que é um dos mais utilizados na avicultura. No entanto, o uso indiscriminado de antimicrobianos na produção de frangos de corte toma destaque mundial, 
principalmente no setor avícola. No entanto os antibióticos promotores de crescimento geram organismos resistentes a antibióticos. (Muro et al 2015). Isso permite seu crescimento, multiplicação e apresentam um risco potencial para a saúde do consumidor. Devido a isso se faz necessário o desenvolvimento de alternativas que possam mitigar a utilização de antimicrobianos sem causar impacto no desempenho produtivo dos lotes.

A utilização de óleos essenciais, busca o controle de microrganismos patogênicos, saúde da flora intestinal e um bom desempenho produtivo. Os óleos essenciais, incluindo carvacrol (oriundo do orégano), e cinamaldeído (extraído da canela), são substâncias que possuem atividade antimicrobiana e, portanto, pode substituir à base de antibióticos promotores de crescimento. (Petrolli et al. 2012, Galli et al. 2020, Liu et al. 2019). Além de possuir ações antioxidantes, anti-inflamatórias e propriedades analgésicas (Suntres et al. 2015).

A utilização de aditivos via água de bebida tem sido uma alternativa emergente na avicultura, visto que permite a prática inclusão de outras moléculas ou mesmo nutrientes em determinadas fases de vida do animal, podendo corrigir algum desequilíbrio ligados aos aspectos nutricionais ou mesmo à saúde intestinal. Devido aos óleos essenciais estarem muitas vezes na forma liquida os mesmos podem ser adicionados via água de bebida, através da adição em conjunto de um emulsificante.

Óleo de canela (Cinnamomum zeylanicus) está entre os óleos essenciais mais importantes no mercado mundial. A canela é utilizada mundialmente na culinária e perfumaria devido às suas propriedades oriundas do cinamaldeído. O cinamaldeído possui atividade antimicrobiana devido à sua lipofilicidade de terpenóides e fenilpropanóides que atravessam a membrana, alcançam o interior das células e danificam o sistema enzimático bacteriano (Wang et al., 2009).

O óleo de orégano (Origanum vulgare), possui dois componentes, o carvacrol e o timol que de acordo com Aeschbach et al. (1994), agem sobre a membrana celular bacteriana inibindo a divisão mitótica, causando desidratação nas células, impedindo a sobrevivência de bactérias patogênicas. Efeitos anti-inflamatórios também são relatados, através da inibição da secreção de citocinas liberadas por endotoxinas presente na membrana na parede celular da maioria das bactérias Gram negativas, (Liu et al 2019). Ainda, segundo Zeng et al. (2015), o carvacrol possui efeitos sob aflora intestinal, pois é capaz de manter o equilíbrio e estimular a mucosa intestinal para aumentar a mitose em criptas de vilosidades, aumentando o número de células e consequentemente aumentando tamanho das vilosidades, resultando em nutrientes melhorados absorção.

Já o óleo essencial de eucalipto (Eucalyptus globulus) possui moléculas ativas, como mentol e 1,8-cineol, que podem gerar sensação de frescor, estimulação do sistema imunológico, inibição de respostas inflamatórias e efeito antimicrobiano (Rehman et al., 2013). Awaad et al. (2010) destacaram os efeitos antimicrobianos e imunoestimuladores do óleo de eucalipto no trato respiratório das aves, melhorando as respostas imunes e reduzindo a incidência de agressão da mucosa no trato respiratório de galinhas.

Diversos trabalhos na literatura Fachii et al, (2019), Rehman et al., (2013), Zeng et al. (2015), Leite et al. (2021), Liu et al. (2019) já demonstraram efeitos positivos quando adicionados via ração, entretanto são necessárias maiores pesquisas sobre os seus efeitos quando adicionados via água de bebida

Portanto, objetivou-se avaliar o efeito da adição de óleos essenciais via água de bebida, como promotores de crescimento em frangos de corte, sobre o desempenho (ganho de peso, consumo de ração, conversão alimentar e mortalidade), parâmetros bioquímicos e histomorfometria intestinal.

\section{Metodologia}

A presente pesquisa foi conduzida pelo Núcleo de Ciência e Pesquisa Aplicada a Monogástricos - NUPAM, na Universidade do Oeste de Santa Catarina - UNOESC Xanxerê, campus II. O experimento foi aprovado pelo comitê de Ética de uso de animais (CEUA/UNOESC), sob parecer CEUA 49/2019, sendo o mesmo elaborada em metodologia quantitativa (Pereira et al., 2018), 
Foram utilizados 450 pintos, machos da linhagem ROSS, vacinados no incubatório com vacinação in-ovo contra doença de Marek e Gumboro, e no primeiro dia de vida via spray contra Bronquite Infecciosa. Foram distribuídos no primeiro dia de idade, em delineamento experimental inteiramente casualizado, sendo composto por quatro tratamentos. (Tabela 1), constituídos por seis repetições, com 15 animais em cada repetição. Os óleos foram adicionados na água de bebida durante todo o período experimental, sendo diluídos em caixas da agua, com capacidade para 500 litros cada, com auxílio de um emulsificante.

Tabela 1. Tratamentos utilizados.

\begin{tabular}{lll}
\hline Tratamento & Aditivo $(\mathbf{g} /$ Ton ou ppm) & Dosagem \\
\hline T1 & Controle negativo & - \\
T2 & Controle positivo - Flavomicina pó & $2 \mathrm{ppm}$ \\
T3 & Carvacrol + Cinamaldeído & $300 \mathrm{ml} / 1000 \mathrm{~L}$ \\
T4 & Óleo de Eucalipto & $300 \mathrm{ml} / 1000 \mathrm{~L}$ \\
\hline
\end{tabular}

Fonte: Autores.

Os animais foram alojados em boxes de $2 \mathrm{~m} 2 \mathrm{em}$ cama de maravalha, criados de acordo com as normas e manejos das granjas comerciais e do manual de linhagem, com ração (Tabela 2) e água a vontade via nipple, durante todo o período experimental.

Tabela 2. Composição alimentar e nutricional da ração referência do experimento.

\begin{tabular}{|c|c|c|c|}
\hline Ingrediente & Inicial & Crescimento & Final \\
\hline Milho, $\mathrm{g} / \mathrm{kg}$ & 476,66 & 508,25 & 651,16 \\
\hline Farelo de Soja (46\%), g/kg & 433,38 & 392,12 & 304,33 \\
\hline Óleo de Soja, g/kg & 45,90 & 61,85 & 48,96 \\
\hline Fosfato Bicálcico, g/kg & 19,43 & 14,53 & 10,92 \\
\hline $\begin{array}{l}\text { Calcário, g/kg } \\
\text { Sal, g/kg } \\
\text { DL-Metionina (99\%), g/kg } \\
\text { L-Lisina } \mathrm{HCl}, \mathrm{g} / \mathrm{kg}\end{array}$ & $\begin{array}{l}8,20 \\
4,55 \\
3,55 \\
2,19\end{array}$ & $\begin{array}{l}8,35 \\
4,25 \\
2,60 \\
3,16\end{array}$ & $\begin{array}{l}7,14 \\
4,07 \\
2,54 \\
2,22\end{array}$ \\
\hline Cloreto Colina $(60 \%), \mathrm{g} / \mathrm{kg}$ & 1,00 & 1,00 & 1,00 \\
\hline Suplemento vitamínico ${ }^{1}, \mathrm{~g} / \mathrm{kg}$ & 20,00 & 20,00 & 20,00 \\
\hline Suplemento mineral ${ }^{2}, \mathrm{~g} / \mathrm{kg}$ & 20,00 & 20,00 & 20,00 \\
\hline L-Treonina & 0,83 & 0,66 & 0,63 \\
\hline L-Valina & 0,34 & 0,00 & 0,00 \\
\hline Valores Calculados & & Quantidade & \\
\hline Energia Metabolizável. kcal/kg & 3050 & 3200 & 3250 \\
\hline Proteína bruta, $\mathrm{g} / \mathrm{kg}$ & 243,00 & 226,20 & 195,40 \\
\hline Lisina digestível., $\mathrm{g} / \mathrm{kg}$ & 13,63 & 12,35 & 10,67 \\
\hline Met. + Cis. digestível, $\mathrm{g} / \mathrm{kg}$ & 9,89 & 9,14 & 7,90 \\
\hline Treonina digestível, $\mathrm{g} / \mathrm{kg}$ & 8,86 & 8,15 & 7,04 \\
\hline Triptofano digestível, $\mathrm{g} / \mathrm{kg}$ & 2,80 & 2,57 & 2,15 \\
\hline Valina digestível, $\mathrm{g} / \mathrm{kg}$ & 10,29 & 9,51 & 8,22 \\
\hline Cálcio, g/kg & 9,50 & 8,22 & 6,61 \\
\hline Fósforo disponível, g/kg & 4,80 & 3,84 & 3,09 \\
\hline Sódio, g/kg & 2,25 & 2,11 & 2,01 \\
\hline
\end{tabular}

${ }^{1}$ Suplemento Vitamínico contendo por kg do produto: Vit. A - 10.000.000 U.I.; Vit. D3 - 2.000.000 U.I.; Vit. E - 30.000 U.I.; Vit. B1 2,0g; Vit. B2 - 6,0g; Vit. B6 - 4,0g; Vit. B12 - 0,015g; Ácido Pantotênico - 12,0g; Biotina - 0,1g; Vit. K3 - 3,0g; Ácido Fólico - 1,0g; Ácido Nicotínico - 50,0g; Selênio - 250,0mg; e Excipiente q.s.p - 1000g; 2Suplemento mineral contendo por kg do produto: Ferro $100,0 \mathrm{~g}$; Cobalto - 2,0g; Fonte: Autores. 


\section{Avaliação de Desempenho Zootécnico}

Para a avaliação do consumo da dieta, ganho de peso e conversão alimentar, todas as aves e dietas foram pesadas aos 7, 21, e 42 dias do experimento, para determinação do ganho de peso, do consumo de ração e da conversão alimentar. Adicionalmente, foi calculada a mortalidade e o Índice de Eficiência Produtiva (IEP).

\section{Parâmetros de Bioquímicos e Histomorfometria Intestinal}

Aos 42 dias de idade, foi abatida uma ave por unidade experimental, por deslocamento e desarticulação cervical, seguindo as normas de bem-estar animal e as normas de eutanásia descritas pelas diretrizes de prática de eutanásia do CONCEA (BRASIL/MCTI, 2013), para as coletas de sangue e fragmento do jejuno.

Para a avaliação dos parâmetros bioquímicos, será utilizado o método de coleta de sangue através da veia braquial, coletando-se $1 \mathrm{ml}$ por animal. O soro será separado por centrifugação e estocado a $-20^{\circ} \mathrm{C}$ para posterior análise das concentrações séricas de proteínas totais, albumina, globulina, colesterol, glicose, enzima Aspartato-aminotransferase (AST), e ácido úrico. As provas bioquímicas serão efetuadas por meio de kit comercial, da marca Analisa, específicos para cada um dos referidos parâmetros, medidos em analisador semi-automático Bioplus 2000. Os níveis de globulinas serão determinados pela diferença entre proteínas totais e albumina.

Para avaliação de morfometria intestinal, os fragmentos de intestino delgado foram coletados para análise histológica intestinal. As amostras intestinais coletadas foram incluídas em parafina e seccionadas entre 4 e 6 em um micrótomo e fixadas em lâminas histológicas. As lâminas foram coradas pela técnica da hematoxilina para posterior análise com Imagepro \Plus 1.3.2 (1994) (aumento de 40x) em microscópio óptico. Para cada lâmina, 30 vilosidades e 30 criptas foram selecionadas e medidas para obtenção do valor médio de cada segmento. Para avaliação da relação vilosidade / cripta, o valor da altura das vilosidades intestinais foi dividido pelo valor da profundidade da cripta adjacente.

\section{Análise Estatística}

Os resultados experimentais serão submetidos ao teste de normalidade Shapiro Wilk, e na sequência será efetuada análise de variância. Na ocorrência de efeito significativo, os dados serão submetidos ao teste de Tukey, a 0,05 de significância, por meio do software estatístico R.

\section{Resultados}

\section{Performance Zootécnica}

Na Tabela 3 estão apresentados os dados de desempenho, cujos frangos alimentados com Flavomicina aos 20 dias de idade apresentaram peso corporal inferior ( $\mathrm{P}=0,029)$ quando comparados aos frangos suplementados com óleo de eucalipto. As aves que receberam flavomicina na dieta apresentaram menor consumo de ração $(\mathrm{P}=0,004)$ quando comparadas as aves pertencentes ao tratamento controle negativo e as aves que receberam óleo de eucalipto via agua de bebida. Nas aves suplementadas com os demais aditivos avaliados, não foram constatadas alterações significativas. Entretanto, aos 42 dias de idade, não houveram alterações $(\mathrm{P}>0,05)$ sobre o peso corporal das aves, porem houve maior consumo de ração dos frangos suplementados com óleo de eucalipto $(\mathrm{P}<0,001)$. Não foram constatadas alterações na conversão alimentar das aves entre os diversos tratamentos avaliados em todos os períodos testados $(P>0,05)$. Não foram encontradas diferenças $(P>0,05)$ no índice de eficiência produtiva (IEP) entre as aves submetidas aos diferentes tratamentos avaliados. 
Tabela 3. Desempenho de frangos de corte suplementados com diversos aditivos

\section{1-7 dias}

\begin{tabular}{|c|c|c|c|c|c|c|c|}
\hline Tratamento & $\begin{array}{l}\text { Peso vivo } \\
\text { (g) }\end{array}$ & \multicolumn{2}{|c|}{$\begin{array}{l}\text { Ganho de peso } \\
\text { (g) }\end{array}$} & \multicolumn{2}{|c|}{$\begin{array}{l}\text { Consumo de } \\
\text { ração }(\mathrm{g})\end{array}$} & CA & Mortalidade \\
\hline Controle Negativo & 153 & \multicolumn{2}{|c|}{107} & \multicolumn{2}{|c|}{148} & $1,35 b$ & $5,65 \mathrm{~b}$ \\
\hline Flavomicina $15 \mathrm{ppm}$ & 153 & \multicolumn{2}{|c|}{107} & \multicolumn{2}{|c|}{151} & $1,40 \mathrm{a}$ & $0,00 \mathrm{a}$ \\
\hline Fitogênicos 200 ppm & 146 & \multicolumn{2}{|c|}{100} & \multicolumn{2}{|c|}{137} & $1,37 \mathrm{ab}$ & $0,00 \mathrm{a}$ \\
\hline $\begin{array}{c}\text { Fitogênicos + Leveduras } \\
200 \mathrm{ppm} \\
\end{array}$ & 152 & \multicolumn{2}{|c|}{106} & \multicolumn{2}{|c|}{140} & $1,32 \mathrm{~b}$ & $0,00 \mathrm{a}$ \\
\hline Valor P & 0,142 & \multicolumn{2}{|c|}{0,142} & \multicolumn{2}{|c|}{0,215} & 0,035 & 0,044 \\
\hline $\mathrm{CV}(\%)$ & 7,23 & \multicolumn{2}{|c|}{7,16} & \multicolumn{2}{|c|}{8,11} & 5,32 & 9,22 \\
\hline \multicolumn{8}{|c|}{ 1-21 Dias } \\
\hline Tratamento & $\begin{array}{l}\text { Peso vivo } \\
\text { (g) }\end{array}$ & \multicolumn{2}{|c|}{$\begin{array}{l}\text { Ganho de peso } \\
\text { (g) }\end{array}$} & \multicolumn{2}{|c|}{$\begin{array}{l}\text { Consumo de } \\
\text { ração }(\mathrm{g})\end{array}$} & $\mathrm{CA}$ & $\begin{array}{l}\text { Mortalidade } \\
\qquad \%)\end{array}$ \\
\hline Controle Negativo & 866 & \multicolumn{2}{|l|}{821} & \multicolumn{2}{|c|}{1127} & 1,37 & $6,70 \mathrm{~b}$ \\
\hline Flavomicina $15 \mathrm{ppm}$ & 864 & \multicolumn{2}{|l|}{816} & \multicolumn{2}{|c|}{1128} & 1,38 & $2,23 \mathrm{a}$ \\
\hline Fitogênicos 200 ppm & 811 & \multicolumn{2}{|l|}{752} & \multicolumn{2}{|c|}{1058} & 1,40 & $5,64 \mathrm{~b}$ \\
\hline $\begin{array}{c}\text { Fitogênicos + Leveduras } \\
200 \mathrm{ppm}\end{array}$ & 863 & \multicolumn{2}{|l|}{815} & \multicolumn{2}{|c|}{1108} & 1,36 & $3,33 \mathrm{a}$ \\
\hline Valor P & 0,212 & \multicolumn{2}{|c|}{0,212} & \multicolumn{2}{|c|}{0,198} & 0,112 & 0,023 \\
\hline $\mathrm{CV}(\%)$ & 5,32 & \multicolumn{2}{|l|}{5,25} & \multicolumn{2}{|c|}{7,33} & 6,33 & 8,44 \\
\hline \multicolumn{8}{|c|}{ 1-42 Dias } \\
\hline Tratamento & $\begin{array}{l}\text { Peso vivo } \\
\text { (g) }\end{array}$ & $\begin{array}{l}\text { Ganho de } \\
\text { peso }(\mathrm{g})\end{array}$ & $\begin{array}{r}\text { Consu } \\
\text { raçãa }\end{array}$ & $\begin{array}{l}\text { mo de } \\
\text { o (g) }\end{array}$ & $\mathrm{CA}$ & Mortalidade & IEP \\
\hline Controle Negativo & $2715 \mathrm{a}$ & $2668 \mathrm{a}$ & 43 & 13 & 1,59 & $7,80 \% a$ & 366 \\
\hline Flavomicina $15 p p m$ & $2690 \mathrm{ab}$ & $2649 \mathrm{ab}$ & 43 & 84 & 1,62 & $4,45 \% \mathrm{~b}$ & 366 \\
\hline Fitogênicos 200 ppm & $2656 b$ & $2606 b$ & 42 & 95 & 1,62 & $7,80 \% a$ & 361 \\
\hline $\begin{array}{c}\text { Fitogênicos + Leveduras } \\
200 \mathrm{ppm}\end{array}$ & $2757 \mathrm{a}$ & $2707 \mathrm{a}$ & 44 & 33 & 1,61 & $6,70 \% a$ & 381 \\
\hline Valor P & 0,046 & 0,045 & 0,2 & 284 & 0,195 & 0,039 & 0,145 \\
\hline $\mathrm{CV}(\%)$ & 6,53 & 6,23 & 7 & 38 & 6,33 & 9,64 & 9,23 \\
\hline
\end{tabular}

*Valores com letras diferentes na mesma coluna diferem entre si pelo teste Tukey a 0,05 de significância. CA - Conversão alimentar. IEP - Índice de eficiência produtiva. CV - Coeficiente de variação. Fonte: Autores. 


\section{Parâmetros Bioquímicos}

$\mathrm{Na}$ Tabela 4 estão representados os parâmetros bioquímicos sanguíneos, nos quais houve diferença apenas sobre os níveis de ácido úrico na dieta de animais, cujas aves pertencentes ao grupo que recebeu flavomicina demonstraram níveis superiores $(\mathrm{P}=0,038)$ quando comparadas com as aves submetidas aos demais tratamentos. Na avaliação da glicose, proteínas totais, albumina, globulina, triglicerídeos e colesterol, não houve influência dos diferentes tratamentos $(\mathrm{P}>0,05)$.

Tabela 4. Parâmetros bioquímicos sanguíneos de frangos de corte suplementados com diferentes aditivos na dieta.

\begin{tabular}{lcccccc}
\hline & $\begin{array}{c}\text { Controle } \\
\text { negativo }\end{array}$ & Flavomicina & $\begin{array}{c}\text { Canela }+ \\
\text { Orégano }\end{array}$ & Eucalipto & CV & Valor P \\
\hline Glicose & 142 & 138 & 127 & 160 & 26,22 & 0.844 \\
Proteínas totais & 3,56 & 4,08 & 4,10 & 4,46 & 16,01 & 0.178 \\
Albumina & 1,44 & 1,46 & 1,34 & 1,50 & 18,40 & 0.829 \\
Globulina & 2,12 & 2,62 & 2,76 & 2,96 & 16,34 & 0.280 \\
Triglicerídeos & 76,4 & 74,0 & 79,4 & 93,0 & 15,23 & 0.754 \\
Colesterol & 159,6 & 146,6 & 169,4 & 151,4 & 19,34 & 0.887 \\
Ácido Úrico & $3,14 \mathrm{~b}$ & $5,58^{\mathrm{a}}$ & $3,26 \mathrm{~b}$ & $3,34 \mathrm{~b}$ & 13,33 & 0.038 \\
\hline
\end{tabular}

*Valores com letras diferentes na mesma linha diferem entre si pelo teste Tukey a 0,05 de significância. CV Coeficiente de variação.

\section{Morfometria Intestinal}

Referente a análise morfométrica intestinal (Tabela 5), não houveram alterações $(\mathrm{P}>0,05)$ na altura de vilosidade intestinal, profundidade de cripta e relação vilo: cripta dos frangos de corte submetidos aos diferentes tratamentos avaliados.

Tabela 5. Análise histológica intestinal de frangos de corte suplementados com diferentes aditivos na dieta.

\begin{tabular}{lcccccc}
\hline & $\begin{array}{c}\text { Controle } \\
\text { negativo }\end{array}$ & Flavomicina & $\begin{array}{c}\text { Canela }+ \\
\text { Orégano }\end{array}$ & Eucalipto & $\begin{array}{c}\text { CV } \\
(\%)\end{array}$ & $\begin{array}{c}\text { Valor } \\
\mathbf{P}\end{array}$ \\
\hline $\begin{array}{l}\text { Altura de } \\
\text { Vilosidade }(\mu \mathrm{m})\end{array}$ & 614 & 710 & 652 & 722 & 16.11 & 0.384 \\
$\begin{array}{l}\text { Profundidade de } \\
\text { Cripta }(\mu \mathrm{m})\end{array}$ & 67 & 63 & 69 & 76 & 21.08 & 0.583 \\
$\begin{array}{l}\text { Relação } \\
\text { Vilo:Cripta }\end{array}$ & 9.79 & 12.57 & 10.34 & 9.95 & 19.39 & 0.107 \\
\hline
\end{tabular}

*Valores com letras diferentes na mesma linha diferem entre si pelo teste Tukey a 0,05 de significância. CV Coeficiente de variação.

\section{Discussão}

Na Tabela 3 estão apresentados os dados de desempenho, as aves suplementadas com óleo de eucalipto via água de bebida desenvolvem maior ganho de peso, quando comparado com o tratamento que continha o promotor de crescimento flavomicina e demais aditivos. Petrolli et al. (2019) observou peso corporal significativo aos 35 dias de idade no tratamento via água de bebida contendo óleo de eucalipto, portanto, concluiu-se que pode ser usado para frangos de carne estressados pelo 
calor sem prejudicar seu desenvolvimento. Ainda Flees et al. (2020), observou eficiência produtiva através da modulação de um anuropeptídio hipotalâmico e orexigênico, em aves suplementadas dieteticamente e via água de bebida, que apresentou melhora significativa sob a eficiência alimentar, que foi alcançada através da redução da temperatura corporal central, sem interferir no consumo e consequentemente obtendo ganho de peso de mercado. Ou seja, o óleo de eucalipto promove redução do estresse térmico que consequentemente irá contribuir para uma boa eficiência alimentar e desenvolvimento.

Os produtos fitoterápicos, dentre eles o óleo de Eucalipto, podem funcionar como um agente antibacteriano contra bactérias produtoras de urease e atenuar o nível ambiental de amônia mitigando sua produção em galpões avícolas e como imunoestimulante em aviários. Este efeito pode aumentar a resistência não específica das aves contra problemas respiratórios leves (Rehman et al. 2013). Hashemi e Davodi (2011), avaliaram uma mistura de óleos essenciais, formada por óleos oriundos da extração de orégano, alho, limão, alecrim, timo, eucalipto e laranja doce, nos quais, aos sete dias de idade não foi possível observar efeito positivo dos óleos essenciais sobre os parâmetros morfológicos avaliados no duodeno. Zardo et al. (2015) consideraram efeitos inertes dos óleos essências do primeiro aos sete dias de idade, pois, não observaram diferença sobre a altura de vilo e profundidade de cripta nos animais tratados, concluindo que os óleos essenciais não afetam parâmetros intestinais do duodeno. A capacidade absortiva do intestino é proporcional ao número de vilosidades ali presentes, e sabe-se ainda que, em animais jovens, a digestão de gorduras é ineficiente pela baixa produção de enzimas digestivas como lipase pancreática e deficiência de produção de bile, além do intestino delgado encontrar-se imaturo. As gorduras apresentam maior dificuldade de digestão e absorção, visto que o intestino delgado não se encontra totalmente maturo Vieira e Moran (1999) pois o desenvolvimento da mucosa é estimulado por agentes tróficos, ou seja, aqueles que estimulam o processo mitótico na região cripta-vilo, como consequência há o aumento do número de células e no tamanho do vilo.

Hernández et al. (2019), avaliaram os efeitos de dois óleos essenciais de orégano mexicano, de Poliomintha longiflora Gray e Lippia berlandieri Schauer, em água potável sobre desempenho por um período de 40 dias, e observaram ganho de peso semelhante para ambos os tratamentos, concluindo que os óleos essenciais de orégano mexicano podem servir como aditivos alternativos naturais para melhorar a produção de frangos e a qualidade da carne. Isso pode ser explicado pela sua ação anti-inflamatória capaz de inibir secreção de citocinas inflamatórias que possuem ação direta no sistema imunológico, que se ativado excessivamente, pode desencadear estresse imunológico como resultado (Liu et al 2019).

A análise bioquímica sérica indicou que os óleos essenciais não provocaram alterações metabólicas no organismo, o que poderiam influenciar nas taxas de oxigenação dos tecidos, e no metabolismo em geral. Esses achados conferem com Facchi et al (2019) e Leite et al (2021), os quais não encontraram efeitos deletérios dos óleos essenciais na dieta dos frangos de corte perante os parâmetros bioquímicos. Petrolli et al (2018), não encontraram efeito da utilização de óleo de eucalipto sobre alterações metabólicas no corpo que influenciem na taxa de oxigenação dos tecidos, o que é muito comum em frangos mantidos em ambientes de estresse térmico.

Os óleos essenciais foram capazes de manter a saúde intestinal das aves conforme o promotor de crescimento Flavomicina. Facchi et al. (2019), avaliaram o uso de carvacrol e cinamaldeído micro encapsulados na dieta de frangos de corte, e observaram aumento de vilosidades, cripta e da relação vilo-cripta, indicando melhora a saúde intestinal. Além de não oferecer efeitos deletérios nós parâmetros bioquímicos, apresentou melhor digestibilidade de nutrientes e consequentemente bom aproveitamento de dietas, sendo assim de uso seguro como antimicrobiano.

Resultados semelhantes foram encontrados por Leite et al (2021), quando avaliou o uso de fitogênicos em combinação ou não com leveduras para frangos de corte, onde ao avaliar a relação vilo/cripta, constatou maior relação nos frangos pertencentes ao tratamento fitogênicos + leveduras, em comparação às aves que receberam flavomicina na dieta. Entretanto, alterações significativas foram observadas na profundidade de cripta das aves, sendo maior nas aves suplementadas com Flavomicina quando comparadas com as aves que receberam os fitogênicos + leveduras na dieta. Sabe-se que o carvacrol e o 
cinamaldeído ajudam a diminuir os impactos causados por bactérias patógenas na parede intestinal além, de atuar na síntese de muco e enzimas digestivas, diminuindo a carga bacteriana (Mustafa et al., 2006).

O sistema imune intestinal tem a imunoglobulina A (SIgA), como principal molécula efetora, pois é capaz de impedir que vírus, bactérias ou algum antígeno nocivo adiram ao epitélio intestinal, gerando imunidade humoral e celular. Liu et al. (2019), avaliaram o fornecimento oral de óleos essenciais de carvacrol para frangos de corte, demonstrando diminuição da expressão gênica de SIgA na mucosa intestinal, mas nenhuma diferença estatisticamente significativa foi encontrada. No entanto Sun et al. (2015), mostrou que os óleos essenciais, compostos por timol e carvacrol, são capazes de diminuir a concentração de SIgA no íleo, indicando que não houve inflamação e/ou invasão intestinal.

A suplementação dietética com aditivos fitogênicos não afeta negativamente o desempenho zootécnico de frangos de corte ou histologia intestinal. Ainda aumenta as respostas imunes e a qualidade intestinal (Fascina et al., 2017).

\section{Conclusão}

Concluiu-se que os óleos essenciais de canela, orégano e eucalipto via água de bebida, não influenciam o desempenho zootécnico de frangos de corte. Da mesma forma, não afetam os parâmetros de mucosa intestinal e bioquímicos séricos.

Estas informações poderão servir de base para a elaboração de futuros programas de substituição de antibióticos na avicultura, podendo embasar futuras pesquisas nesta área.

\section{Agradecimentos}

Agradecimento ao programa de bolsas universitárias de Santa Catarina - UNIEDU Art. 171, pela concessão da bolsa de iniciação científica.

\section{Referências}

Aeschbach, R., Löliger, J., Scott, B. C., Murcia, A., Butler, J., Halliwell, B. \& Aruoma, O. I. (1994). Antioxidant actions of thymol, carvacrol, 6-gingerol, zingerone and hydroxytyrosol. Food and Chemical Toxicology, 32, 31-36.

Awaad, M. H. H.; Abdel-Alim, G. A., Sayed, K. S. S., Kawkab, A., Ahmed, A., Nada, A. A., Metwalli, A. S. Z. \& Alkhalaf, A. N. (2010). Immunostimulant effects of essential oils of peppermint and eucalyptus in chickens. Pakistan Veterinarian Journal 30, 61-66.

Brasil. Ministério da Ciência, Tecnologia e Inovação. (2013). Diretrizes para a prática de eutanásia do CONCEA. MCTI.

Facchi, C. S., Valentini, F. D. A., Aniecevski, E., Leite, F., Rossatto, G., Dal Santo, A.; Zaccaron, G.; Bosetti, G. E.; Henkes, K. I.; Da Silva, A. S.; Tavernari, F. de C. \& Petrolli, T. G. (2019). Carvacrol e cinnamaldeído microencapsulados melhoram o aproveitamento dos nutrientes e mantem a integridade da mucosa intestinal de frangos de corte. Avicultura Industrial, 1291.

Galli, G. M., Gerbet, R. R., Griss, L. G., Fortuoso, B. F., Petrolli, T. G., Boiago, M. M., Souza, C. F., Baldissera, M. D., Mesadri, J., Wagner, R., Rosa, G., Mendes, R. E., Gris, A. \& Da Silva, A. S. (2020). Combination of herbal components (curcumin, carvacrol, thymol, cinnamaldehyde) in broiler chicken feed: Impacts on response parameters, performance, fatty acid profiles, meat quality and control of coccidia and bacteria. Microb pathog, 139 , e103916.

Hashemi, S. R. \& Davoodi, H. (2011) Herbal plants and their derivatives as growth and health promoters in animal nutrition. Veterinary Research Communications, 35, 169-180.

Hernández-Coronado, A. C, Silva-Vázquez, R., Rangel-Nava, Z. E, Hernández-Martínez, C. A, Kawas-Garza, J. R, Hume, M. E, \& Méndez-Zamora, G. (2019). Óleos essenciais de orégano mexicano dados na água potável para desempenho, características de carcaça e qualidade da carne de frangos de corte. Poultry Science, 98(7), 3050-3058.

Flees, J., Greene, E., Ganguly, B. (2020). Phytogenic feed and water-additives improve feed efficiency in broilers via modulation of (an)orexigenic hypothalamic neuropeptide expression, Neuropeptides, https://doi.org/10.1016/ j.npep.2020.102005

Leite, F., Pagnussatt, H., Dal Santo, A., Valentini, F. D. A., Talian, L. E., De Lima, M., Aniecevski, E., Zaccarom, G., Galli, G. M., Tavernari, F. C., Da Silva, A. S. \& Petrolli, T. G., Avaliação da utilização de fitogênicos em combinação ou não com leveduras em substituição a antibióticos para frangos de corte. Research, Society and Development, 10(6), e4510615384.

Liu, S. D., Song, M. H., Yun, W., Lee, J. H., Kim, H. B. \& J. H. Cho, J. H. Effect of carvacrol essential oils on immune response and inflammation-related genes expression in broilers challenged by lipopolysaccharide. 2019 Poultry Science 98:2026-2033. 
Research, Society and Development, v. 10, n. 8, e11210817007, 2021

(CC BY 4.0) | ISSN 2525-3409 | DOI: http://dx.doi.org/10.33448/rsd-v10i8.17007

Muro, E. M., Pelicia, V. C., Vercese, F., Souza, I. M. G. P., Pimenta, G. E. M., Oliveira, R. S. S. G. \& Sartori, J. R. (2015). Aditivos fitogênicos e glutamina mais ácido glutâmico na dieta de frangos desafiados com coccidiose. Revista Agrarian, 8, 304-311.

Mustafa, A., El-Medany, A., Hagar, H. H., \& El-Medany. G. (2006). Ginkgo biloba attenuates mucosal damage in a rat model of ulcerative colitis. Pharmacological Research. 53, 324-330.

Pereira A. S. et al. (2018). Metodologia da pesquisa científica. UFSM.

Petrolli, T. G., Albino, L. F. T., Rostagno, H. S., Gomes, P. C., Tavernari, F. C. \& Balbino, E. M. (2012). Herbal extracts in diets for broilers. Revista Brasileira de Zootecnia, 41: 1683-1690.

Petrolli, T. G., Sutille, M. A., Petrolli, O. J., Stefani, L. M., Simionatto, A. T., Tavernari, F. C., Zotti, C. A. \& Girardini, L. K. (2019). Eucalyptus oil to mitigate heat stress in broilers. Revista Brasileira de Zootecnia, 48, e20160306.

Rehman, S. R., Muhammad, K., Yaqub, T., Khan, M., Hanif, K. \& Yasmeen, R. (2013). Antimicrobial activity of mentofin and its effect on antibody response of broilers to newcastle disease virus vaccine. The Journal of Animal \& Plant Sciences, 23, 1008-1011.

Sun, Q., Liu, D., Guo, S., Chen, Y \& Guo, Y. (2015). Effects of dietary essential oil and enzyme supplementation on growth performance and gut health of broilers challenged by clostridium perfringens. Animal Feed Science and Technology, 207, 234-244.

Suntres, Z. E., Coccimiglio, J. \& Alipour, M. (2015). The bioactivity and toxicological actions of carvacrol. Critical Reviews in Food Science and Nutrition, $55,304-318$.

Vieira, S. L. \& Moran, E. T. (1999). Effect of egg of origin and chick post-hatch nutrition on broiler live performance and meat yields. World's Poultry Science Journal, 55, 126-142.

Wang, R., Wang, R., Yang. (2009). Extraction of essential oils from five cinnamon leaves and identification of their volatile compound compositions. Innovative Food Science \& Emerging Technologies, 10, 289-292.

Zardo, A., Otutumi, L. K., Do Amaral, P. F. G., Germano, R. M., Ferreira, F. A., Dourado, M. R. \& Mezalira, T. S. (2015). Dietas suplementadas com óleos essenciais não promove alterações na morfometria de vilos e criptas do duodeno de frangos de corte. Arquivos de Ciências Veterinárias e Zoologia da UNIPAR, 18(2), 115-119.

Zeng, Z., Zhang, S., Wang, H. \& Piao, X. (2015). Essential oil and aromatic plants as feed additives in non ruminant nutrition: a review. Journal of Animal Science and Biotechnology, 6, 1-10. 